\title{
Social Network as a Knowledge Service Provider
}

\author{
${ }^{1}$ Shalev Tammy, ${ }^{2}$ Guy Shilon, ${ }^{3}$ Adi Wolfson, ${ }^{4}$ Dorith Tavor, ${ }^{5}$ Shlomo Mark* \\ ${ }^{1}$ Software Engineering Department, Sami Shamoon College of Engineering, Bialik/Basel Sts. Beer-Sheva, \\ 84100, Israel \\ shalev.tammy@gmail.com \\ ${ }^{2}$ Software Engineering Department and Negev Monte Carlo Research Center (NMCRC), Sami Shamoon \\ College of Engineering, Bialik/Basel Sts. Beer-Sheva, 84100, Israel \\ gshilon@gmail.com \\ ${ }^{3}$ Green Processes Center, Sami Shamoon College of Engineering, Bialik/Basel Sts. Beer-Sheva, 84100, \\ Israel \\ adiw@sce.ac.il \\ ${ }^{4}$ Green Processes Center, Sami Shamoon College of Engineering, Bialik/Basel Sts. Beer-Sheva, 84100, \\ Israel \\ dtavor@sce.ac.il \\ ${ }^{5}$ Software Engineering Department and Negev Monte Carlo Research Center (NMCRC), Sami Shamoon \\ College of Engineering, Bialik/Basel Sts. Beer-Sheva, 84100, Israel
}

marks@sce.ac.il

*Corresponding author: marks@sce.ac.il, Tel: 972-8-8519078, Fax: 972-8-8519062

\section{ABSTRACT}

One of the most important challenges facing humanity today is the design and development of more sustainable processes - those that balance the needs of the present generation without compromising the ability of future generations to meet their own needs. The Sustainability as Service Science model $\left(S^{\wedge} 3\right)$ presents a novel perspective of the relationship between sustainability and services in the framework of service science by defining both sustainable services and sustainability as service and by describing the mutual relationship between sustainability and service. Informationrich, the field of sustainability in many ways suffers from information overload, which can foster uncertainty and confusion during any decision-making process. In this study we present a new social network framework, in which the social network is an 'information to knowledge' service that shares knowledge, in the process evaluating its correspondence to and trustworthiness within the field of sustainability. Guided by the three basic principles of awareness, responsibility, and commitment, the new information to knowledge framework is conceptualized as a platform from which to transform the plethora of information available in the field of sustainability into practical and trusted knowledge.

Keywords: Sustainability; Service Science; Social Network; information to knowledge; trust.

\section{Council for Innovative Research}

\author{
Peer Review Research Publishing System
}

Journal: International Journal of Management \& Information Technology

\author{
Vol.4, No.1 \\ editor@cirworld.com \\ www.cirworld.com, member.cirworld.com
}




\section{INTRODUCTION}

"Sustainability is a measure of the capacity of a certain process or state in any system to balance the needs of the present without compromising the ability of future generations to meet their own needs" (Wolfson et al. 2010)[1]. One of the most important challenges humanity faces today, therefore, is the design and development of more sustainable production and service processes. Part of that challenge is entailed in the need, during the design and implementation of sustainable services, to meet customer demands in a way that can be perpetuated for long periods of time without negatively affecting either the natural or the social environment. This design should be imbued with sustainability not only as an essential part of each service "core-value," but also as a "super-value" that allows and motivates the customer to become a sustainability provider to the next generation (Dong et al. 2008)[2].

With sustainability as top priority, the service rationale should comprise the three pillars of awareness, responsibility, and commitment. The first pillar refers to acknowledging the effects human actions have had and can have on nature in general and on the environment in particular. In the twenty-first century, for example, that must include increasing our awareness of the human contribution to the greenhouse effect, an actual threat produced largely by forest clearing and the burning of fossil fuels those results in carbon dioxide emissions (U.S. Department of Commerce 2005.)[22]. Cognizance of the direct and indirect effects of our behavior is followed first by the development of a sense of responsibility for our actions as individuals and as a society and then by expression of a commitment to take concrete action to effect positive change. Yet to imbue the design and use of services with sustainability while fostering an atmosphere that encourages both provider and customer to have as their common goal performing the service more sustainably will require the corresponding data, information, and knowledge to achieve those goals.

When discussing knowledge as a service and addressing the internet as a vast network of human information whose referenced books function collectively as a source of knowledge, the definitions of the concepts of information and knowledge must be refined. While information is the capture and processing of data, knowledge comprises what we know in the form of facts, concepts, or skills (Bellinger et al. 2004)[23]. The transformation of information to knowledge is basically dependent on our level of trust of the sources of the information, and in a sense it relies on how, given our experience, we rate the information.

In this paper we present a new social network designed to function as a service framework that transforms the available information on sustainability into reliable knowledge by sharing and exchanging that knowledge. But for the knowledge obtained to be deemed reliable, the social network must also include a trust assignment functionality, because the extent to which data and information are trustworthy is a principal concept behind the transformation of information to reliable knowledge. The general idea of the new social network, therefore, is to enable the principles of sustainability to be propagated via a social network that is a platform to gather validated information, to manage highly accessible and reliable knowledge, and to streamline more effective decision making processes. The exploitation as such of a social networking service will promote a flexible system for obtaining and learning reliable knowledge about sustainability by encouraging users to create personal profiles and to share information, knowledge, and tools with others who are subscribed to the network. However, a topological analysis to define the optimal social network for maximizing efficiency and will not be part of this discussion (Valdis 2011)[7].

\section{DISCUSSION}

\subsection{Social network as a service to produce trusted sustainability knowledge}

Although both our knowledge and awareness of environmental risk and sustainable development have increased tremendously in the last decade, practical application of the theory of sustainability is complicated and has been limited. Defining sustainability as a service of the current generation to subsequent generations is one of the methods used to promote the practical implementation of sustainability theory (Wolfson et al. 2010,2011,2012)[1,4-6]. But despite the field of sustainability being rich and replete with information, its focus is mainly on the environmental aspects-and less on the equally important economic and social dimensions_of sustainability. Moreover, much of the information has not been properly vetted. As such, this glut of information constitutes a formidable barrier, further compounded by the inability to distinguish between high- and low-quality information and to convert it to knowledge, to the adoption of more sustainable behavior.

Indeed, the enormous amount of information thus far generated in the field of sustainability suffers from a lack of proven knowledge, the direct result of which is manifested in the excess of tools and methods often developed to the same end. Consider, for example, calculation of the carbon footprint, a measure of the amount of greenhouse gasses emitted during a given activity (e.g., production processes). The abundance of computational tools and methods that have been used to calculate the carbon footprint has engendered a critical lack of clarity about the correct calculation pathway and uncertainty in the validity of the corresponding values that emerge from such ambiguity (Kates et al. 2001)[3]. Thus, while one can rapidly amass a tremendous amount of information about carbon footprints (e.g., definitions, calculations, 
etc.), processing, validating, and converting that raw information to dependable knowledge is nearly impossible, thereby eliciting the need for automated software that relies on principles of artificial intelligence.

The social network, which constitutes one of the most popular platforms for sharing information, is defined by its structurenodes and links and by its behavioral interactions among the nodes and links (Lewis 2009)[24]. Network science is the study of the theoretical foundation of network structure and behavior using approaches such as graph theory. Within network science, the study of networks is an applied sub-field and its analysis (in terms of structure, emergence, dynamism, autonomy, bottom-up evolution, topology, power, and stability) enables focused access to and subtle monitoring of the social network. Social networks can be used as a platform to share information and knowledge that focuses on facilitating the construction of relations among people who, for example, share interests, activities, backgrounds and so on. A social network service consists of a representation of each user's social links and a variety of additional services (Wellman et al. 1996)[9]. Though the social network today is mainly identified with Facebook, there are many more focused and specialized social network systems. Linkedln, for example, is a social networking site designed specifically for the business community. The goal of this network is to allow registered members to establish and document networks of people they know and trust professionally. It means that if user A is connected to user B, they trust each other and most likely interact, or have interacted, on a professional basis. However, low supervision together with a basic algorithm of social network analysis results in no surety of the specified 'trust' between entities in the network.

The rising popularity of social networks has made information sharing and discovery easier than ever before, due to the ability to publish content to large and targeted audiences (Taylor and Rozi 2010)[8]. "Such networks enable their participants to simultaneously become both consumers and producers of content while shifting the role of information broker from a few dedicated entities to a diverse and distributed group of individuals" (Canini et al. 2011)[10]. As this fundamental change allows information consumers more flexibility in choosing what content to follow, it makes it necessary for users to access a vast pool of potential choices to discover, evaluate, and select sources of information that are worthy of their attention (Serrato 2009)[11]. Hence, a social network that allows sharing and exchanging information about sustainability can be used as a service to evaluate this information and as a framework to provide verified and reliable knowledge about sustainability.

Preliminary work has shown that the amount of data about the environmental aspects of sustainability are much larger than that of its social or economic characteristics (Vallance 2011; U.S. Department of Commerce 2005)[20,21] (Figure 1). As this current distribution of data is far from optimal and because a significant part of it is not trusted, one of the targets of social network analysis is to serve as an automated computational tool to characterize the distribution of information clustering reflected in three main perspectives (i.e., environmental, social and economic) for which sustainability must account.

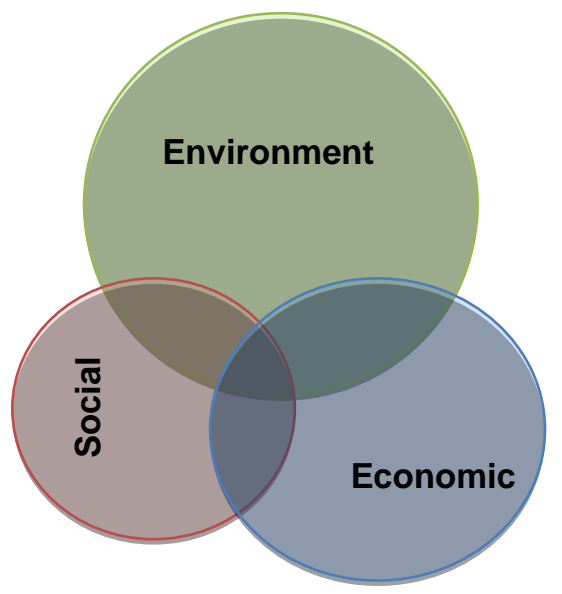

Available

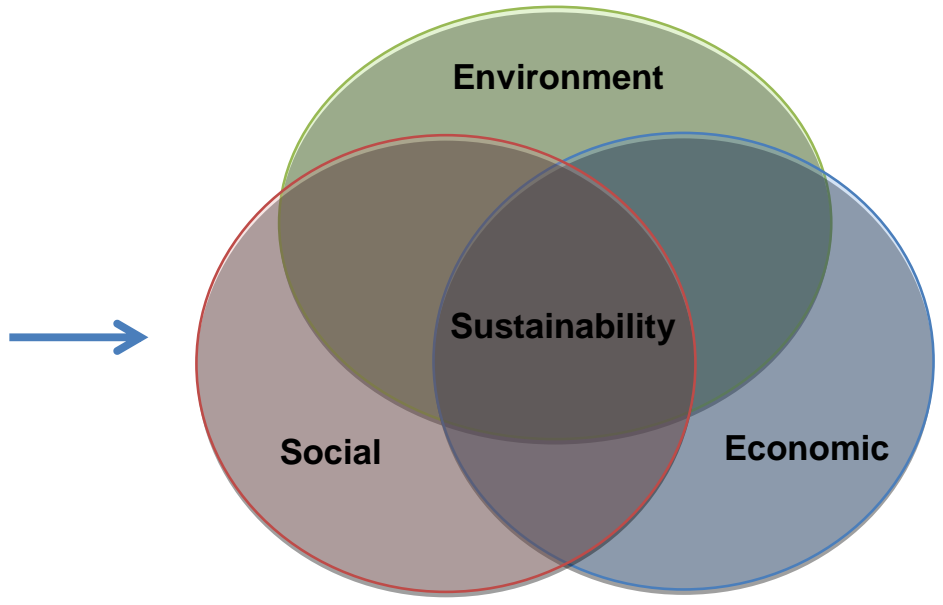

Desirable

Figure 1: Available distribution vs. desirable distribution of sustainability resources.

The value representing the relevance of each element to sustainability is also of paramount concern, and hence, it must integrate the impact of each of the three perspectives on sustainability. In the framework of the new social network, therefore, each perspective will be assigned a numerical estimate in the range of zero to one that reflects its relevance to sustainability. Each piece of information is thus evaluated using as a three-dimensional vector corresponding to the three sustainability aspects. For example, in Figure 2 article 'a1', which represents a given piece of information that will be 
uploaded to the network, is represented by vector $S(x, y, z)$, where $x, y$, and $z$ are positive numbers between zero (no attachment) and one (full attachment), such that the value of each is indicative of its relevance to sustainability. $A$ Cartesian coordinate system for a three-dimensional space means choosing an ordered triplet of lines (axes) that share a single unit of length. The coordinates of a point $p$ can be taken as the (signed) distances from $p$ to the three planes defined by the three axes. If the axes are named $x, y$, and $z$, then the $x$ coordinate is the distance from the plane defined by the $y$ and $z$ axes. A point in space $p$, therefore, represents the estimated trust of each sustainability aspect. If we arbitrarily assign the $x$-axis to Economy, the $y$-axis to Society, and the z-axis to Environment, the coordinates (i.e., estimates) of article 'a1' indicate that it is related by 0.3 to Economy, by 0.6 to Society, and by 0.9 to Environment (Fig. 2 ). The last part of the assessment process entails weighting the results. Once a resource has been estimated as a threedimensional vector $\mathrm{S}(\mathrm{x}, \mathrm{y}, \mathrm{z})$, the length (magnitude or norm) of the vector $\mathrm{S}$, which is denoted by $\|\mathrm{S}\|$ or less commonly by $|S|$, will be calculated as the Euclidean norm

$$
\|\mathbf{a}\|=\sqrt{a_{1}^{2}+a_{2}^{2}+a_{3}^{2}}
$$

The value generated by this computation represents the extent to which the resource is in fact relevant to sustainability, and as such, it is one of the parameters of an element's trust value in the social network.

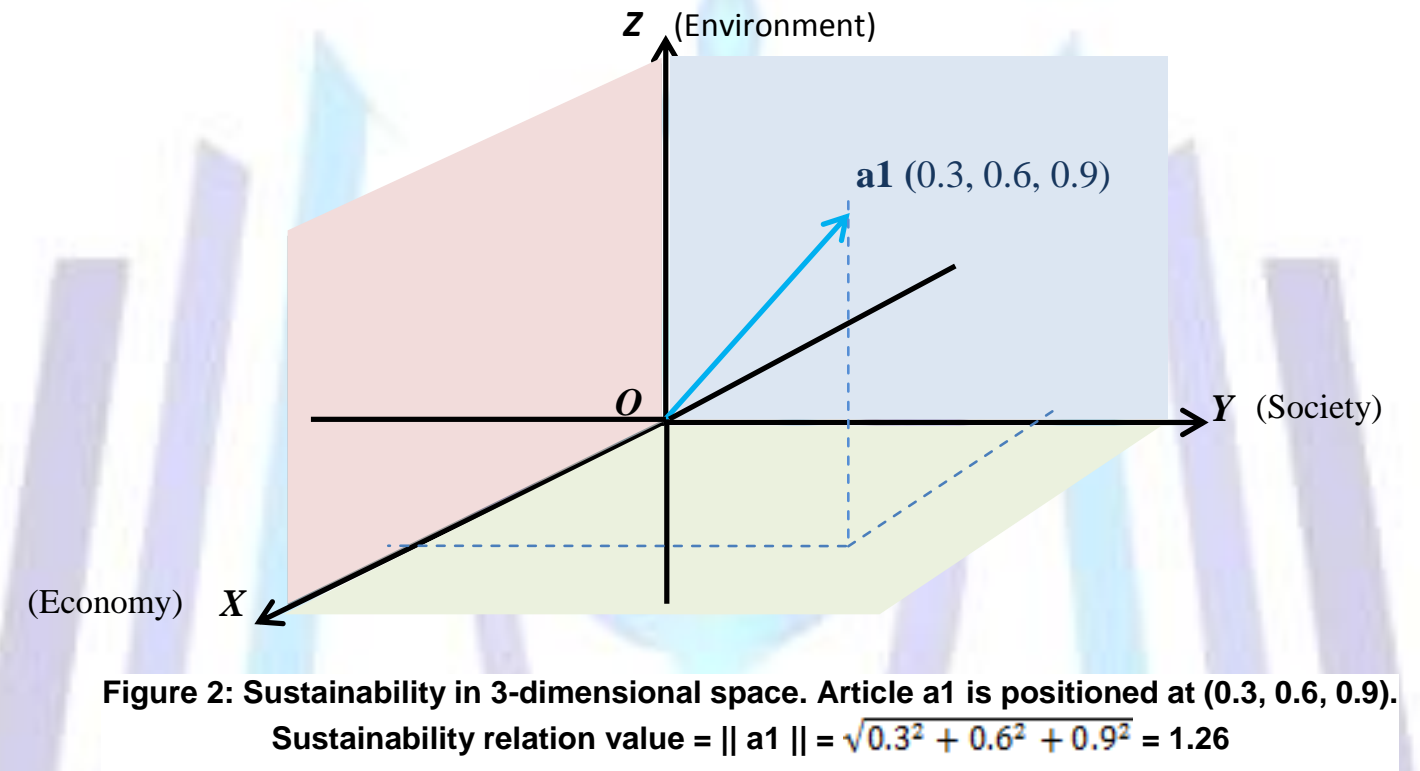

\subsection{Trust formalism as a tool for converting information to knowledge}

In the search for reliable information and knowledge, the trustworthiness of the result is critical. Living as we do in the socalled information age, we benefit from the sheer volume of data that are easily accessible via the Internet, but the credibility of the information contained therein is highly uncertain. Consider Wikipedia, for example: as a free encyclopedia that anyone can freely edit, there is no concrete guarantee as to the tenability of the information it contains. Another goal of the new social network, therefore, is the rigorous evaluation of all of its sources.

The difficult task of quantifying trust can exploit the fact that many computing systems contain information that is produced and processed by numerous people. Therefore, knowing the extent to which a given user trusts a source can be useful for aggregating, filtering, and ordering the information (Kuter and Golbeck 2007)[13]. In addition, if trust is used to support decision making, it is important to have an accurate estimate of trust, and a measure of confidence in that estimate, when it is not directly available (Kinateder et al. 2005)[14]. Among a few known trust algorithms that we considered implementing in our study, the PageRank algorithm (Benincasa et al. 2006)[15] was designed to analyze links and numerically weight each element of a hyperlinked set of documents (e.g., URLs) to determine its relative importance within the set. The value associated with each element is therefore the rating received based on a variety of parameters. In terms of the $S^{\wedge} 3$ model, however, the PageRank algorithm is less relevant due to the modified definition of 'trust' adopted within the framework of sustainability. Its inflexible and strict calculation of trust lacks any reference to the relevance of a given source of information to sustainability as a parameter, a key element to the model's agenda.

As the demand for knowledge rises there is growing need for a system or a platform that will monitor the data. Several studies have been done on the concept of transforming information to knowledge (Bin and Munindar 2006; Boanerges et al. 2006; Boragatti 2001; Jones 2001)[16-19], yet none focused on a network, such as a social network, whose elements are dependent on each other. In the frame of the new social network, the transformation of information to knowledge will 
entail each element (user, source) undergoing an inherent trust evaluation process. Trust will then be a value associated with each element in the social network at any given time. For example, a newly subscribed network user or uploaded article will be given an initial trust value based on some static and general parameters.

Once subscribed to the social network, each user will be able to participate in the activities provided within the network (e.g., uploading resources, rating other users, etc.). Each activity completed by the user will be accompanied by the user's trust value changing dynamically according to an algorithm designed to quantify the updated trust value based on the user's latest network activity.

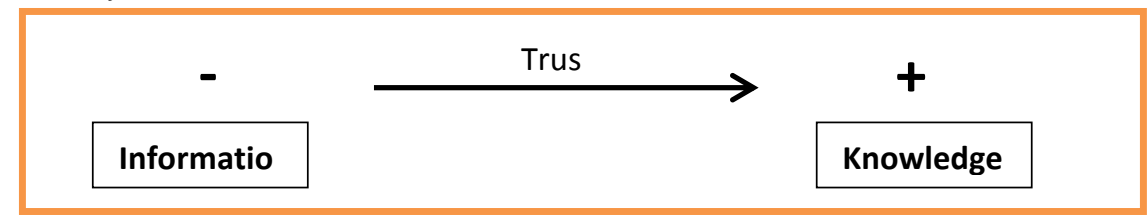

Figure 3: Information is considered knowledge only after its trust value

The initial trust value that a new element (user, source) receives is negative, which means that the element has positioned itself based on how it was presented to the social network (Fig. 3). For example, new subscribers to the network must answer a questionnaire, and they will each be granted an initial trust value calculated from the information conveyed in their responses about their backgrounds and about their self-perceptions of their sustainability positions. But the activities of other users of the social network ultimate determine an element's trustworthiness. An element is thus considered to be "information" as long as its trust value (self-positioned) is negative (Fig. 3). Only after the trust value becomes positive, is the element considered knowledge (Fig. 4). For instance, an element positioned at $(3,4,2)$ can be considered to be knowledge in terms of all three perspectives (Economy, Society and Environment) of sustainability, but one positioned at $(2,-1,2)$ is rated as knowledge in terms of the economic and environmental dimensions of sustainability but as information from the social perspective. Using this approach, the initial trust value of a new user or source can change only through the activities of other users in the social network. And because the calculations of user trust values are dynamic, trust value changes with each new activity performed by the user. For example, if a user posts an article he/she wrote to the network and included in the article is a positive reference to a another network user, then the trust value of the other user increases accordingly. The extent of the influence each activity has on the trust value, however, has yet to be determined and should be the focus of additional research.

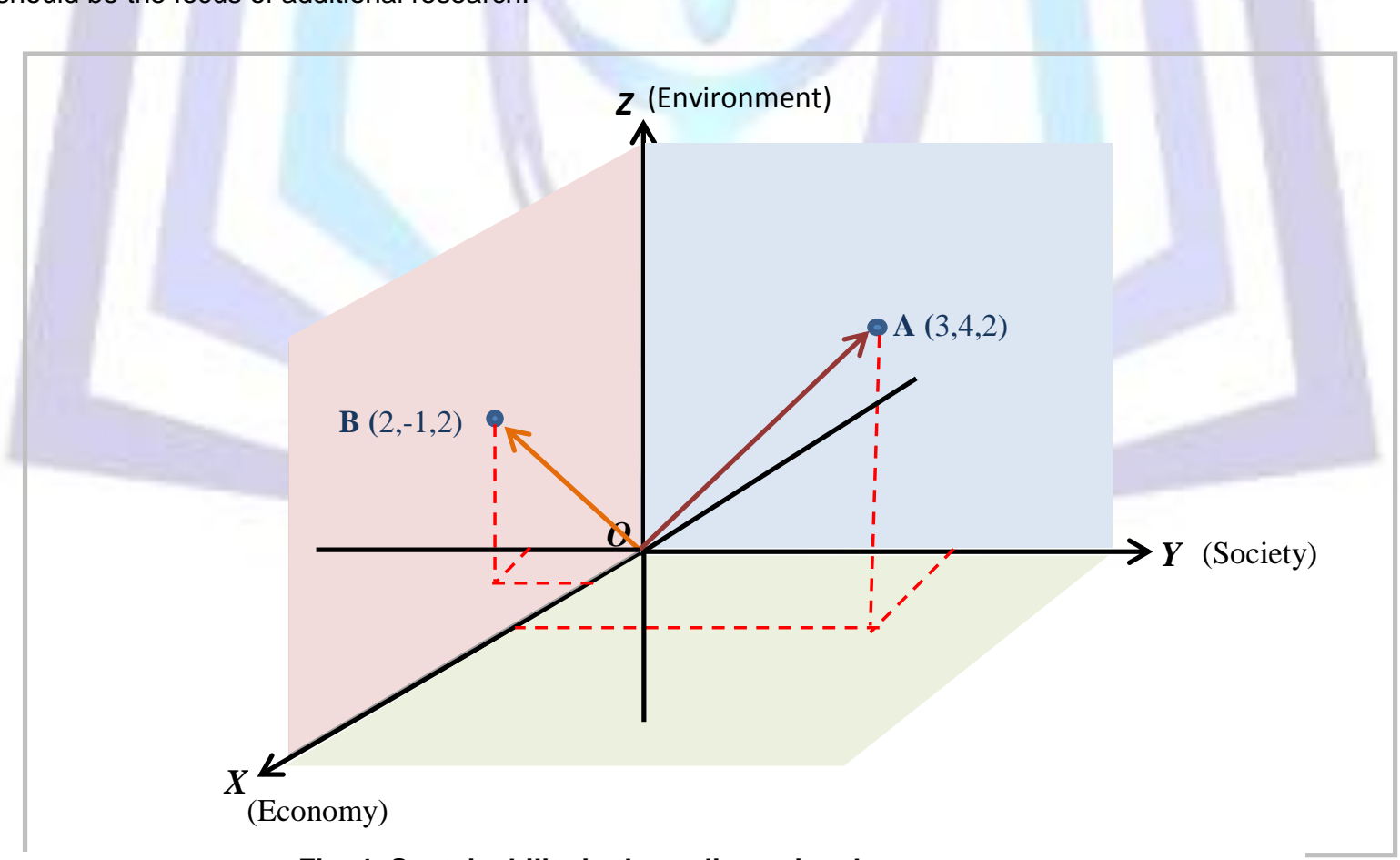

Fig. 4: Sustainability in three-dimensional space.

Several parameters must be considered when establishing the trust value for a user or for a source in the social network. The first are User Trust Parameters, which refer to the user's reputation- academic status, type of employment, and so on, the number of sources published by the user in the social network, the user's degree of involvement in the social network, i.e., the number of ratings, number of added tags, and so on, the rating of a user's published sources, etc. The 
second group of parameters is Source Trust Parameters, which comprise the relevance of that source to sustainability, the trust value given to the publisher of the source, the ratings given to the source together with the trust values of the users who provided the ratings, number of views and downloads of the source, number of tags, etc.

Trust values thus change dynamically after every user activity in the social network and according to the type of user (i.e., the user's trust value) who performs the action. Accordingly, how the initial trust value of the user is determined-i.e., the relative weights assigned to each parameter-when that user subscribes to the social network must be considered. The selection of a suitable algorithm, each of which prioritizes trust components differently, is essential. For example, an algorithm that gives greater weight to source relevance to sustainability or, alternatively, to the number of downloads will generate a trust value that is respectively weighted. The choice of the "correct" algorithm, therefore, must entail an informed decision, the components of which we have yet to determine.

\section{CHLLENGES}

In this study we have presented a new social network as a framework to share knowledge about sustainability while evaluating both its correspondence to the field and its credibility. As the notion has only been theoretically discussed and has yet to be tested in real time, we predict that $S^{\wedge} 3$ model implementation (Wolfson et al. 2010,2012)[1,6] in the framework of the new social network will face many challenges.

Among the issues that arose during this study was recognition of the need to map the types of users participating in the network, which could facilitate implementing shifts in trust values based on the affiliation of the user performing an activity. For example, users can be classified into two groups-researchers and interested. By definition, a researcher has permissions to perform a greater number of activities than an interested user, and if individuals from both groups rate the same article, the rating the researcher gave should receive greater weight. But at present, because the classification of user types is based on all the activates enabled in the social network, this has yet to be completed.

Another challenge to implementing a social network for collaborating on and propagating notions of sustainability relates to the bias in the data toward the environmental aspect of sustainability and the corresponding neglect of its societal and economic dimensions. As such, we anticipate that any data analysis will reveal a corresponding imbalance in the available information that will make implementation of the $S^{\wedge} 3$ model ineffective. In other words, while the model is based on source relation to sustainability as a whole, the network in the scenario described will be environmentally inclined, and it will not be able to provide a complete picture of sustainability until the missing societal and economic data are added.

In addition to the problem of incomplete data, social networks are open to intentional abuse on the part of their users, who can generate misleading trust evaluations by 'promoting' certain subjects or sources for personal gain. This can be achieved, for example, by users' deliberately conspiring in advance, a scenario facilitated by the typically easy and open subscription process (i.e., anyone can subscribe) characteristic of social networks, which are limited in the extent to which they can verify the personal information provided by their members. Because all social network platforms currently struggle with this problem, the work of identifying potential solutions is ongoing.

\section{CONCLUSIONS}

One of the main objectives of this research was to establish the guiding principles of a social network framework that will monitor trusted knowledge in the field of sustainability. Work toward achieving a reliable definition of trust has indicated the need for an algorithm that considers a variety of parameters to calculate the trust value of a source.

Milestones for this project include a data mining process and the creation of a trust algorithm that will be integrated within a social network designed and implemented to efficiently transform information to knowledge.

\section{REFERENCES}

[1] Wolfson, A., Tavor, D., Mark, S., Schermann, M., Krcmar, H. S3. 2010. Sustainability and Services Science: Novel Perspective and Challenge' Service Science 2(4). pp. 216-224

[2] Dong, B, Evans, K. R., and Zou, S. 2008. The effects of customer participation in co-created service recovery J. of the Acad. Mark. Sci. 36, pp. 123-137

[3] Kates, R.W, Clark, W.C., Corell, R, Hall, J.M., Jaeger, C.C., et al. 2001. 'Environment and development: sustainability science' Science 292(5517). Pp. 641-42

[4] Wolfson, A, Tavor, D, Mark, S, Schermann, M, and Krcmar, H. 2011. 'Better Place: A case study of the reciprocal relations between sustainability and service' Service Science 3(2). pp. 172-181

[5] Wolfson, A, Tavor, D, Mark, S. 2011. 'Sustainable Services: the Natural Mimicry Approach' Journal of Service Science and Management 4(2). Pp.125-131.

[6] Wolfson, A, Tavor, D, Mark, S. 2012. Sustainability and shifting from a 'person to person' to a super- or selfservice. J. of $u$ - and e- Ser. Sci. and Tech. 5. 25-34.

[7] Valdis, K, Social Network Analysis. 2011. Orgnet.com.

[8] Taylor, G, Rozi, K. 2010. 'Current Issues and Trends: Social Networking' ETT 501: Northern Illinois University.

[9] Wellman, B., Salaff J., et al. 1996. 'Computer networks as social networks: Virtual community, computersupported cooperative work and telework' Annual Review of Sociology Vol. 22. pp. 213-238

[10] Canini, K, Suh, B, and Pirolli, P. 2011. 'Finding credible information sources in social networks based on content and social structure' In 2011 IEEE International Conference on Privacy, Security, Risk, and Trust, and IEEE International Conference on Social Computing.

[11] Serrato, O. 2009. 'Social Network Analysis' Asian Development Bank.

[12] Kuter, U, Golbeck, J. 2007. 'SUUNY: A New Algorithm for Trust Inference in Social Network Using Probabilistic Confidence Models' Proceedings of the national conference on AAAl, pp. 1377--1382. 
[13] Kinateder, M., Baschny, E., Rothermel, K. 2005. Towards a generic trust model - comparison of various trust update algorithms. In: Herrmann, P., Issarny, V., Shiu, S.C.K. (eds.) Trust 2005. LNCS, vol. 3477, pp. $177-192$. Springer, Heidelberg.

[14] Benincasa C., Calden A., Hanlon E., Kindzerske M., Law K., Lam A. 2006. Page Rank Algorithm.

[15] Bin Yu, Munindar P.Singh. 2003. Searching Social Networks.

[16] Jones P.M. Collaborative knowledge management, Social Networks, And Organizational learning'.

[17] Colantonio, A, (Oxford Brookes University). 2007. Social sustainability; a review and critique of traditional versus emerging themes and assessment methods.

[18] Vallance, S, Perkins H.C., Dixon, J.E. 2011. What is social sustainability? A clarification of concepts.

[19] U.S. Department of Commerce. 2005. Carbon Cycle Science. NOAA Earth System Research Laboratory. http://www.esrl.noaa.gov/research/themes/carbon/

[20] Bellinger, G, Castro, D, Mills, A. 2004. Data, Information, Knowledge, and Wisdom. URL: http://www.systems thinking.org/dikw/dikw.htm

[21] Lewis T.G. 2009. 'Network Science: Theory and Practice' Hoboken, NJ: John Wiley \& Sons.
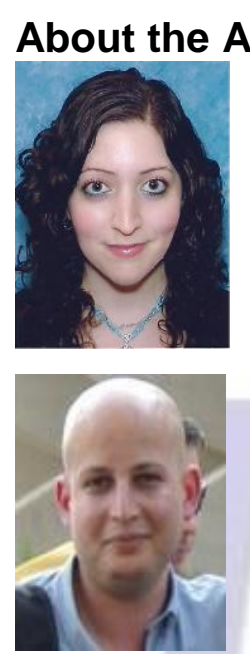

Mr. Guy Shilon is a research-assistant at the Negev Monte Carlo Research Center (NMCRC) at the Sami Shamoon College of Engineering (SCE). Mr. Shilon earned his B.Sc. degree and currently pursuing his M.Sc. degree both in Software Engineering, at the Sami Shamoon College of Engineering, Israel.

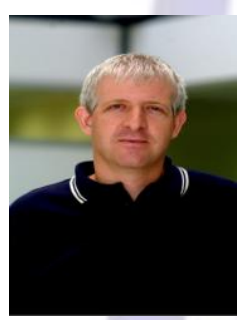

Ms. Tammy Shalev is a research-assistant at the Sami Shamoon College of Engineering (SCE). Ms. Shalev is currently achieved her B.Sc. degree in Software Engineering, at the Sami Shamoon College of Engineering, Israel.

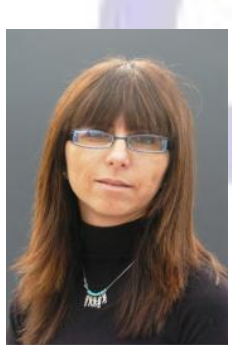

Prof. Adi Wolfson the chair of the Chemical Engineering Dept. and one of the founders of Green Processes Center at Sami Shamoon College of Engineering. Prof. Wolfson earned his PhD summa cum laude in chemical engineering at Ben-Gurion University in Beer-Sheva and continued his postdoctoral in the University of Leuven, Belgium. Prof. Wolfson has worked in the field of green chemistry and engineering for the last 10 years working mainly on catalytic applications in organic reactions and alternative environmentally friendly solvents. Prof. Wolfson is also working with the national and local authorities as well as with the industry on imbuing sustainability and sustainable development in Israel.

Prof. Dorith Tavor is The Dean of Chemical Engineering, Chair of Green Processes Center and Chair of Center of Learning Promotion at Sami Shamoon College of Engineering. Prof. Tavor earned here PhD in chemical engineering and MBA at Ben-Gurion University in Beer-Sheva, Israel. Prof. Tavor found the chemical engineering department and the Green Processes Center at Sami Shamoon College of Engineering. Prof. Tavor has worked in the field of green engineering working mainly on catalytic applications in organic reactions and alternative environmentally friendly solvents and Recycling of industrial wastewater. Prof. Tavor is also imbuing sustainability and sustainable development in academia, community, and industry. Prof. Tavor is responsible in the college on incentive of women and girls to learn science and technology.

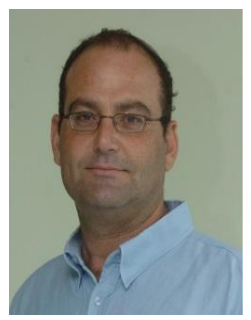

Dr. Shlomo Mark is the chair of the Software engineering Department and the head of the Negev Monte Carlo Research Center (NMCRC) at SCE - Sami Shamoon College of Engineering, Israel. Dr. Mark earned his Ph.D. in 2003 from the department of nuclear engineering, Ben Gurion University of the Negev, Israel, in the field of Experimental Methods and Computational Modeling for Physical and Medical Applications. Dr. Mark received his M.Sc. in Biomedical Engineering and in Managing and Safety Engineering. Dr. Mark main research interests are; Service Science, Agile programming, Sustainability as a service, Scientific software product, Monte Carlo Simulations, Computational modeling for Physical, environmental and medical applications. 